\title{
Phytosterols: natural compounds with established and emerging health benefits
}

\author{
Elke A. TRAUTWEIN \\ Isabelle DEMONTY \\ Unilever Food and Health Research Institute, \\ Unilever R\&D Vlaardingen, \\ Olivier van Noortlaan 120 (PO Box 114), \\ 3130 AC Vlaardingen, The Netherlands \\ <elke.trautwein@unilever.com> \\ Both authors contributed equally to this review
}

\begin{abstract}
Phytosterols (plant sterols and stanols) are naturally occurring compounds which are found in all foods of plant origin. The term phytosterols refers to more than 200 different compounds. The most abundant ones in the human diet are sitosterol and campesterol. Their saturated counterparts, sitostanol and campestanol, are found in much lower amounts. Good food sources of phytosterols include vegetable oils, cereal grains, nuts, legumes, and fruits and vegetables. Phytosterols are structurally similar to cholesterol. Despite this structural similarity, they are not absorbed in significant quantities. Absorption is less than 2\% for phytosterols, while it is 30-60\% for cholesterol. Phytosterols are known to have various bioactive properties, which may have an impact on human health, and as such boosted interest in phytosterols in the past decade. The most important benefit is their blood cholesterol-lowering effect via partial inhibition of intestinal cholesterol absorption. The recommended daily intake of $2 \mathrm{~g}$ of phytosterols reduces cholesterol absorption by $30-40 \%$ and LDL-cholesterol by $10 \%$ on average. Other claimed benefits of phytosterols are possible anti-atherogenic effects as well as, particularly for beta-sitosterol, immune stimulating and anti-inflammatory activities. Furthermore, there is emerging evidence suggesting that particularly plant sterols may have beneficial effects against the development of different types of cancers, like colorectal, breast and prostate cancers. It is not clear whether mechanisms other than the established cholesterol-lowering action of phytosterols as such also contribute to these potential health benefits.
\end{abstract}

Key words: phytosterols, health benefits, cholesterol-lowering, LDL-cholesterol, atherosclerosis, immunity, inflammation, cancer, benign prostate hyperplasia

plant sterols, lacking the double bonds in the steroid nucleus and the alkyl side chain.

In this review, the term phytosterols refers to both plant sterols and their saturated counterparts, the plant stanols. The most biologically relevant phytosterols are sitosterol, campesterol, stigmasterol and brassicasterol. Sitostanol and campestanol, the major plant stanols, are 5,6-saturated analogues of sitosterol and campesterol (figure 1).

The present review will focus on the established and emerging health benefits of phytosterols. Safety aspects have been previously reviewed $[3,4]$ and will not be addressed.

\section{Occurrence and dietary intake of phytosterols}

A comprehensive review of important food sources of phytosterols including aspects of ripening, post-harvest and processing changes in phytosterol contents has recently been published [5]. Appreciable amounts of phytosterols are found in the lipid-rich and fibre-rich fractions of all plant foods. In particular, vegetable oils and products made from oils like spreads and margarine are good sources of plant sterols
[1]. Other foods which contribute to the daily intake of plant sterols are cereal grains, cerealbased products, nuts, legumes, vegetables and fruits $[6,7]$. Plant stanols are also found in some foods, but at much lower concentrations. They are found in some cereals grains like rye, corn and wheat and in non-hydrogenated vegetable oils [1]. Plant stanols are also found in plant material from coniferous trees such as pine and spruce.

Dietary intake of plant sterols ranges from 150 to $400 \mathrm{mg} /$ day with $65 \%$ of intake as $\beta$-sitosterol, $30 \%$ as campesterol and $5 \%$ as stigmasterol $[8,9]$. The daily intake of plant stanols is in the magnitude of about $25 \mathrm{mg} /$ day [10].

\section{Metabolism of phytosterols and their effects on cholesterol absorption}

Despite the structural similarity between cholesterol and the major phytosterols, their absorption by mammalian intestine is low. Absorption rates are $0.5 \%$ for sitosterol, $1.9 \%$ for campesterol, $0.04 \%$ for sitostanol and $0.16 \%$ for campestanol, compared to a choles- 


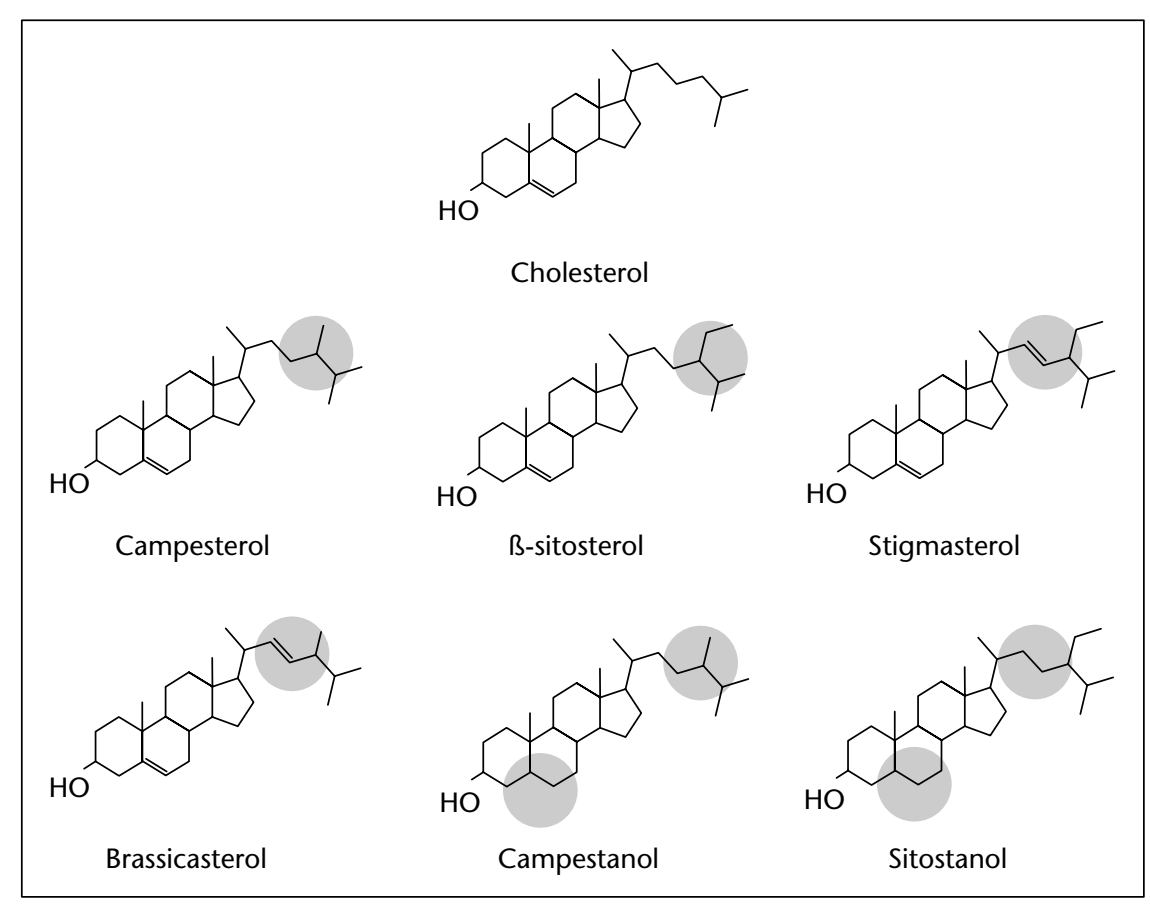

Figure 1. Chemical structure of the most biologically relevant phytosterols.

terol absorption rate of, on average, 56\% [9, 11]. The low absorption of phytosterols as compared to cholesterol is explained by their rapid re-secretion from the intestinal cells back into the gut lumen via the ATP-binding cassette $(A B C)$ transporters $A B C$ G5 and $A B C G 8$ [12].

Phytosterols are absorbed under the same conditions that exist for cholesterol. Like cholesterol, they are taken up in the so-called dietary mixed micelles, which typically contain mixtures of free cholesterol, mono- and di-glycerides, fatty acids, phoshoplipids and bile acids. Like esterified cholesterol, phytosterol esters ingested with the diet need to be hydrolysed by pancreatic cholesterol esterase. Inhibition of intestinal cholesterol absorption is the mechanism of action responsible for the cholesterol-lowering effect of phytosterols. As a consequence, the faecal excretion of cholesterol and its intestinal breakdown products is increased. In several studies, the effect of dietary phytosterol intake on intestinal cholesterol absorption has been directly measured. Intakes of 0.7 to $9 \mathrm{~g} /$ day of phytosterols resulted in a reduction in cholesterol absorption in the range of 7-69\% [13]. The recommended daily intake of $2 \mathrm{~g}$ of phytosterols reduces cholesterol absorption by $30-40 \%$, leading to a $10 \%$ lowering of LDL-cholesterol $[3,13]$.

Although not all details are yet fully elucidated, several mechanisms are thought to contribute to the overall inhibition of intestinal cholesterol absorption by phytosterols [14]. The key mechanism of action is displacement of cholesintake is a crucial step for the formation of dietary mixed micelles. This plays an important from Trautwein et al. [14]. role in the overall mechanism of action and consequently for the optimal cholesterollowering efficacy of phytosterols when consumed with various background diets and in the form of different enriched food formats. For instance, ingestion of a (fatty) meal stimulates bile flow, resulting in a release of (endogenous) cholesterol into the gut lumen, which increases the likelihood for phytosterols to compete with cholesterol for micellisation.

There is also emerging evidence that phytosterols interfere with transporter-mediated processes of cholesterol uptake [16]. Recent insights into the role of so-called influx and efflux sterol transporters in the gut, like the Niemann-Pick C1 Like 1 (NPC1L1) protein and the $A B C$ transporters $A B C G 5$ and $A B C G 8$ have shown that phytosterols and cholesterol share the same transport processes [17]. Figure 2 summarises the various putative mechanisms by which phytosterols lower cholesterol absorption.

As phytosterols interfere with intestinal cholesterol absorption, and fat-soluble vitamins and carotenoids share the same absorption pathway as cholesterol, a potential concern relates to the effects of phytosterols on fat-soluble vitamin and carotenoid absorption. Several studies have shown that intakes of phytosterolenriched foods does not affect plasma concentrations of retinol, vitamin $\mathrm{D}$ and $\mathrm{K}$, but significantly lower plasma concentrations of carotenoids and vitamin $E[3,13]$. As carotenoids and vitamin $E$ are transported by lipoproteins, usually their concentrations are standardised for plasma lipid concentrations. After such lipid standardisation, plasma concentrations of tocopherols remain normally unaltered, while the concentrations of alpha- and beta-carotene and lycopene are up to $20 \%$ lower with phytosterol intake. Carotenoid con-

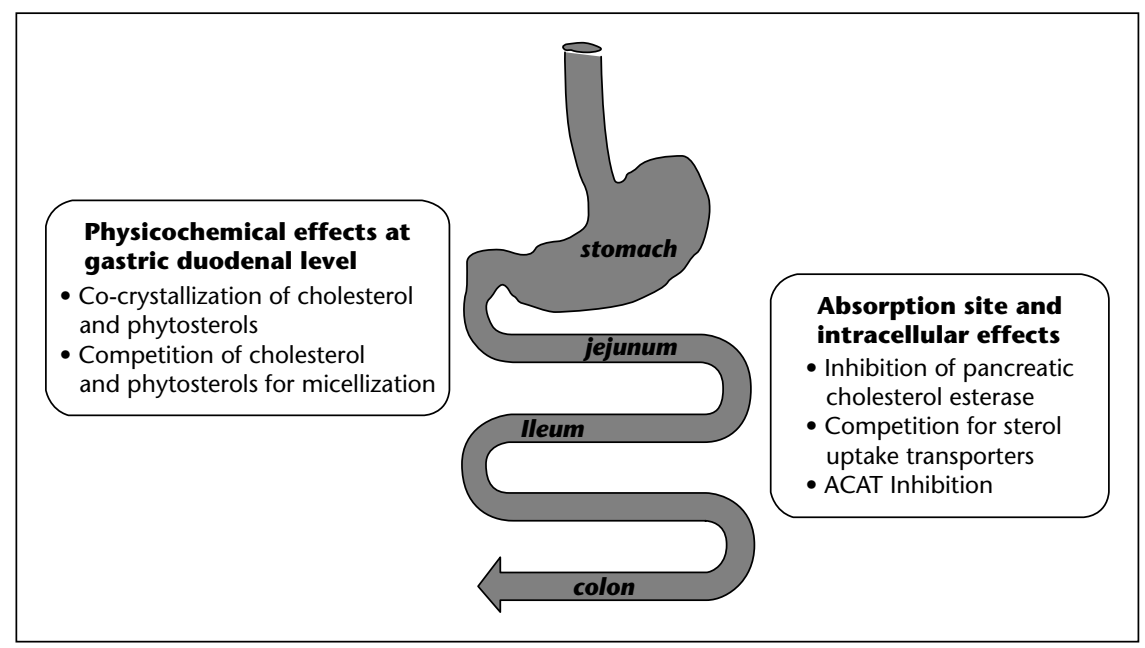

Figure 2. Potential sites of action and mechanisms by which phytosterols may lower cholesterol absorption. Adapted 
centrations remain, however, still within the normal inter-individual range and typical seasonal variations. Moreover, the phytosterolinduced decrease in plasma carotenoid concentrations can be counterbalanced by consuming more fruits and vegetables [3].

\section{Health benefits of phytosterols}

Beneficial effects of phytosterols related to cholesterol metabolism and atherosclerosis risk next to other metabolic processes in the human body have been reviewed recently $[18,19]$.

\section{Plasma cholesterol-lowering}

\section{The early findings}

The most important physiological effect of phytosterols relates to their cholesterol-lowering action. The cholesterol-lowering properties of plant sterols were observed in humans in the early 1950s [20]. Due to the crystalline nature and poor solubility of the pure phytosterol preparations, high doses of up to $50 \mathrm{~g} /$ day were required to achieve a significant cholesterol-lowering effect [21]. A major breakthrough occurred when it was shown in the 1980 s that the esterification of phytosterols with fatty acids from vegetable oils could ease their incorporation into a variety of food products.

\section{Cholesterol-lowering efficacy \\ of phytosterol esters}

A vast number of human studies have shown that phytosterol esters, when incorporated into various food products, significantly lower total and LDL-cholesterol. A recent meta-analysis of 41 clinical trials with fat-based foods like spreads, margarine, mayonnaise or salad dressings enriched with phytosterol esters has shown a non-linear dose-response relationship between the daily dose of phytosterols consumed and cholesterol-lowering efficacy [3]. On average, $2 \mathrm{~g} /$ day phytosterols (the equivalent dose expressed as free sterols based on $3.3 \mathrm{~g} /$ day phytosterol esters) lowered LDLcholesterol concentrations by about 10\% [3] The effect appeared to taper off at intakes of about $2 \mathrm{~g} /$ day or more, with little additional benefit at intakes higher than $2.5 \mathrm{~g} /$ day (Figure 3). Phytosterol esters incorporated in low-fat food matrices such as milk, yoghurt and oncea-day yoghurt/yoghurt drinks have also been shown to significantly lower LDL-cholesterol, with effects ranging from -5 to $-16 \%$ for doses of 1.6 to $3.0 \mathrm{~g} /$ day [22-25].

\section{Cholesterol-lowering efficacy} of free phytosterols

In recent years, considerable effort has been spent to formulate free phytosterols into both

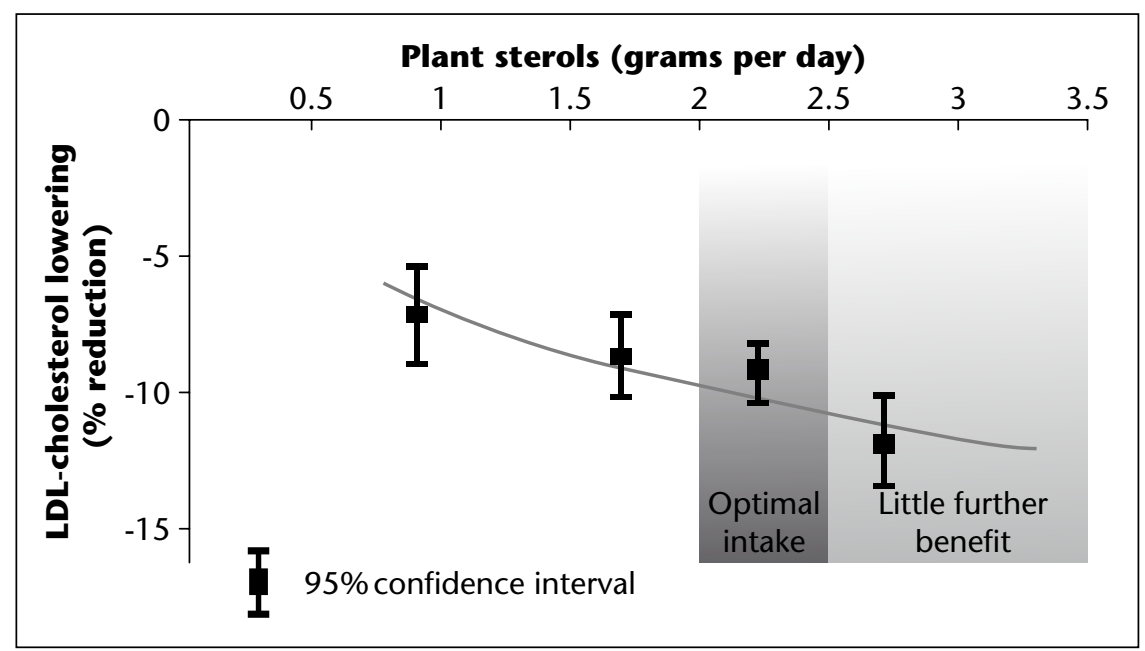

Figure 3. The dose-response relationship between phytosterol intake and LDL-cholesterol lowering effect. Based on Katan et al. [3].

liquid and solid food formats. Different formulations of free phytosterols (phospholipid - lecithin - micelles, micro-crystallised, finely dispersed, or dissolved and then re-crystallised in oil) have been tested in recent human trials. Except for one study which did not show a significant effect of low-fat and non-fat dairy beverages [26], free phytosterols provided in multiple daily doses of fat-free or low-fat beverages such as orange juice and milk have been shown to lower LDL-cholesterol $[27,28]$ to an extent similar to that reported for plant sterol esters in fat-based food formats [3]. Phytosterols incorporated in their free form in fat-based food matrices (margarine, butter) [29, 30] and other fat-rich foods (tortilla chips, chocolate, cold cuts and sausages) [31-33] were also shown to be efficacious in lowering LDLcholesterol. Overall, properly formulated free phytosterols may be as effective as plant sterol and stanol esters in lowering blood cholesterol. However, further studies with a direct head-to head comparison of free vs. esterified phytosterols would be useful to fully clarify this aspect.

\section{Impact of frequency of intake and intake occasion on the cholesterol-lowering efficacy of phytosterol-enriched foods}

From a practical point of view, an important aspect to consider is the extent to which the frequency of intake (i.e. once daily or in divided doses throughout the day) affects the cholesterol-lowering efficacy of phytosterolenriched foods. A study specifically designed to address this question did not show a significant difference in the effects of a phytosterolenriched spread consumed once a day with lunch or three times a day with breakfast, lunch and dinner [34]. Other food formats enriched with phytosterols and consumed once-a-day (yoghurt drink, ground meat) were also shown to significantly lower LDL-cholesterol $[25,35]$. One factor that may affect the cholesterollowering efficacy of phytosterols-enriched foods is their intake occasion. Indeed, consumption of a once-a-day yoghurt drink with lunch was shown to lower LDL-cholesterol concentrations more markedly than consumption on an empty stomach, 30 minutes before breakfast [25]. It may be hypothesized that the stimulation of bile release consequent to the presence of food in the upper part of the gut facilitates the action of phytosterols by stimulating the formation of mixed micelles which are crucial to the process of cholesterol absorption. Moreover, bile contains significant amounts of cholesterol which are less effectively reabsorbed in the presence of phytosterols and are therefore excreted in faeces.

\section{Combination of phytosterols} with other cholesterol-lowering approaches

The LDL-cholesterol lowering effect of phytosterol-enriched foods appears to be additive to that of some other dietary approaches to lower plasma cholesterol. The impact of phytosterols on LDL-cholesterol was evaluated as part of a "heart-healthy" diet (e.g. low or moderate intakes of total and saturated fat) in various clinical trials. When compared with the baseline, usual diet, the healthy dietphytosterol combination led to decreases in LDL-cholesterol of up to $24 \%$ for doses of phytosterols ranging from 1.5 to $2.3 \mathrm{~g} /$ day $[3,36]$. The LDL-cholesterol lowering effect attributed to the healthy diet in these studies was about $10 \%[3,36]$, suggesting an additive effect of phytosterols with the healthy diet.

A more effective way to optimise dietaryinduced cholesterol lowering is to combine phytosterols with other ingredients and func- 


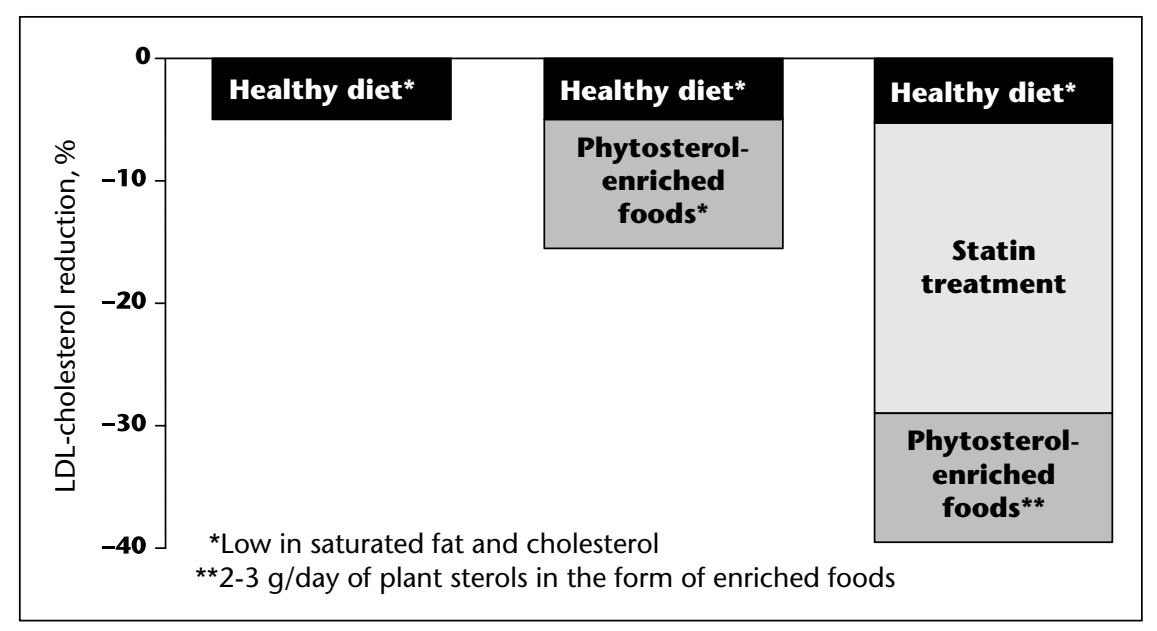

Figure 4. The cholesterol-lowering effect of phytosterols is additive to that of a healthy diet and lipid-lowering medications such as statins. Based on: Katan et al. [3] and Edwards and Moore [44].

tional foods that have different cholesterollowering mechanisms. A good example of such a combination is the "Portfolio diet" which includes viscous dietary fibers such as psyllium or beta-glucan from oats, soy protein, almonds and phytosterols. This diet was shown to lower $\mathrm{LDL}$-cholesterol in hypercholesterolemic individuals by around $30 \%$ within one month [37]. On a longer term (one year), the LDLcholesterol lowering obtained in free-living individuals was about $13 \%$ on average, but reductions in LDL-cholesterol of more than $20 \%$ were achieved in more than $30 \%$ of the fully compliant participants [38]. These results confirmed the contribution of phytosterols to the beneficial effect of the "Portfolio diet" on the long term. Phytosterol ester intake had indeed been shown to consistently lower total and LDL-cholesterrol in long-term efficacy studies lasting up to one year $[39,40]$.

Phytosterol-enriched foods may also be a useful adjunct to specific lipid-lowering medica- tions. Additional cholesterol-lowering benefits have been observed with statins [41] and fibrates [42]. In one large multi-centre clinical trial, statins alone, a phytosterol-enriched spread alone, and the statin-phytosterol combination lowered LDL-cholesterol by $32 \%, 8 \%$ and $39 \%$, respectively, showing that the effects of phytosterols and statins are additive [41]. Phytosterols and ezetimibe, however, were not shown to have additive effects [43], possibly due to the fact that both ezetimibe and phytosterols lower cholesterol absorption, and that a "ceiling" effect may be achieved in lowering cholesterol absorption. Figure 4 shows the cholesterol-lowering effects that can be expected by combining phytosterolenriched foods with a healthy diet and statins $[3,44]$.

\section{Anti-atherogenic effects of phytosterols}

So far, no long-term studies on the effect of phytosterols on atherosclerosis and thus CHD risk reduction in humans are available. However, animal studies have convincingly shown beneficial, anti-atherogenic effects.

Over 30 studies have investigated the effect of phytosterols on experimental atherosclerosis models in different animals, such as chicken, rabbits, hamsters and more recently knockout mouse models [4]. These studies have shown clear protective effects, such as a reduction in arterial lipid accumulation and a reduction in the development of atherosclerosis, e.g. lesser plaque development or reduced lesion size, an inhibition of lesion formation and progression and even regression of existing lesions resulting from the cholesterol-lowering action of phytosterols [45-50]. The key findings related to the evidence from these animal studies are summarised in table 1.

In the more recent studies, different types of genetically modified, so-called knockout mice were studied. In ABC G5/G8 and LDL-receptor double knockout mice fed for 7 months a Western diet, the size of the atherosclerotic lesions was similar to that observed in control mice, despite greatly elevated plasma phytosterol concentrations ( $>20$-fold higher than control mice) [51]. In LDL receptor-deficient mice fed for 35 weeks an atherogenic diet with phytosterols alone or in combination with atorvastatin, less aortic lesion development was observed compared to mice fed the atherogenic diet without phytosterols, despite the 4 to 11 -fold increase in plasma sitosterol and campesterol concentrations resulting from phytosterol intake [52]. Moreover, consumption of phytosterols alone for an additional period of 12 weeks resulted in lesion regression [52]. These findings suggest that elevated plasma sitosterol and campesterol concentrations caused by feeding dietary phytosterols alone or in combination with a statin have no atherogenic effects.

Table 1. Anti-atherosclerotic effects of dietary phytosterols in various animal models.

\begin{tabular}{|c|c|c|c|c|}
\hline Animal studies & Dose (\% weight of diet) & Sterols or stanols & Source & Effects on atherosclerosis development ${ }^{a}$ \\
\hline \multicolumn{5}{|l|}{ Hamsters } \\
\hline Nanios et al., 2003 [49] & $0.24-2.84 \%$ & Pure sterols & Vegetable oil & Reduced lesion formation \\
\hline \multicolumn{5}{|l|}{ Mice } \\
\hline Moghadasian et al., 1997 [45] & $2 \%$ & Mainly sterols & Tall oil & Reduced lesion formation \\
\hline Moghadasian et al., 1999 [47] & $2 \%$ & Mainly sterols & Tall oil & Reduced lesion formation \\
\hline Moghadasian et al., 1999 [48] & $2 \%$ & Mainly sterols & Tall oil & Reduced lesion size \\
\hline Volge et al., 2001 [50] & $1 \%$ & Mainly sterols & $\begin{array}{l}\text { Vegetable oil vs } \\
\text { Wood }\end{array}$ & Reduced extent and severity of lesions \\
\hline Plat et al., 2001 [52] & $1-2 \%$ & $\begin{array}{l}\text { Both sterols and } \\
\text { Stanols }\end{array}$ & Tall oil & $\begin{array}{l}\text { Inhibited lesion formation \& progression regression } \\
\text { of existing lesions }\end{array}$ \\
\hline Rabbits $^{\mathrm{b}}$ & $0.2-3 \%$ & Sterols/ stanols & Not well describeb & Reduced development of lesions \\
\hline Chicken $^{\mathrm{b}}$ & $1-5 \%$ & Sterols/ stanols & Not well describeb & Reduced lesion formation \\
\hline
\end{tabular}

${ }^{\text {a }}$ With respect to control group (where applicable).

${ }^{\mathrm{b}}$ As summarised by Pollak and Kritchevsky [53]. 
In vitro studies utilizing vascular smooth muscle cells (VSMC) isolated from rats have shown that phytosterols stimulated prostacyclin release from VSMC, suggesting that natural phytosterols may prevent VSMC hyperproliferation, which could play a beneficial role against atherosclerosis development [54]. Another in-vitro study with macrophages found a reduced release of prostaglandins, possibly offering protection from atheroma development via affecting platelet aggregation or vasodilatation of blood vessels [55].

Human studies have not demonstrated yet clear possible benefits of phytosterols on other risk factors related to the development of atherosclerosis besides the substantial reduction of total and LDL-cholesterol. For instance, coagulation and fibrinolytic parameters as well as endothelial markers like vascular cell adhesion molecule 1 (VCAM) and intercellular adhesion molecule 1 (ICAM) were not significantly affected after plant sterol or stanol intake for up to 16 weeks $[56,57]$. In studies with children with familiar hypercholesterolemia, short-term phytosterol intake did not improve endothelia dysfunction as measured by flow-mediated dilation (FMD) despite the clear reduction in LDL-cholesterol [58]. Besides LDL-cholesterol lowering, decreased levels of oxidized-LDL were observed with the intake of phytosterols for 4 weeks, suggesting a protection against LDL-oxidation [59]. Whether phytosterols indeed have distinct antioxidant properties and whether these have any relevance to human health awaits further investigation. Therefore, it is still uncertain whether other possible effects next to LDL-cholesterol lowering contribute to the anti-atherosclerotic properties of phytosterols.

\section{Anti-inflammatory effects and effects on the immune system}

Some evidence suggests that phytosterols, particularly beta-sitosterol, may have antiinflammatory activity. In vitro studies showed an inhibition of secretion of inflammatory markers such as interleukin-6 (IL-6) or tumor necrosis factor alpha (TNF- $\alpha$ ) by monocytes [60]. In ovalbumin-induced asthmatic mice, lung inflammation related to leukocytosis and eosinophil infiltration was reduced by intraperitoneal injection of beta-sitosterol [61]. Oral consumption or topic application of a single dose of a phytosterol mixture containing mainly beta-sitosterol was also shown to decrease or even inhibit oedema in murine models of inflammation [62]. However, results from other studies in animal models do not support a role for beta-sitosterol in preventing or reducing inflammation $[63,64]$. In humans, data on the effects of consumption of phytosterol-enriched foods on inflammatory markers are scarce and conflicting. One trial showed a significant reduction in plasma C-reactive protein (CRP) concentrations following consumption, for 8 weeks, of $2 \mathrm{~g} /$ day phytosterols incorporated in a reduced-calorie orange juice [27]. However, in a longer term study, 16-wk consumption of $2.5 \mathrm{~g} /$ day phytosterols did not affect soluble adhesion molecules, CRP and monocyte chemotactic protein-1 concentrations [57]. These latter results suggest that at doses consumed for cholesterol-lowering, phytosterols may not exert noticeable effects on inflammation in human subjects. Nevertheless, further investigations would be useful to address this question in a more comprehensive manner.

To gain insight into the modulatory effects of phytosterols on the immune system, Bouic et al. undertook a series of in vitro, animal and humans studies, and published reviews on this topic $[60,65]$. Beneficial effects of doses of beta-sitosterol as low as $60 \mathrm{mg} /$ day in combination with negligible amounts (less than $1 \mathrm{mg} /$ day) of sterolins (beta-sitosterol glucosides), were reported to improve the immune function in subjects affected by various pathologic processes such as pulmonary tuberculosis, HIV, stress-induced immune suppression, allergic reactions and rheumatoid arthritis [60, 65]. The mechanisms by which beta-sitosterol and beta-sitosterol glucosides would improve the immune response include increases in the proliferative response of blood lymphocytes and in the lytic/cytotoxic activity of natural killer cells, a modulation of the T-helper $1 / T$ helper $2($ Th1/Th2) balance $[60,65]$, as well as effects on macrophage function [66]. A recent study in a mouse model of acute, aseptic inflammation has given further support for a role of dietary phytosterols (a mixture containing $41 \%$ beta-sitosterol) in increasing the Th1/Th2 ratio [64]. However, considering that the phytosterol dose used in human studies (60 $\mathrm{mg} /$ day) $[60,65]$ is low compared with the dose used in the animal trial (2\% of diet weight) [64], and that the normal dietary intake of phytosterols by humans is around $150-400 \mathrm{mg} /$ day, it seems doubtful whether such low additional intakes of phytosterols could result in distinct effects on the immune function in human subjects. Further studies with doses of phytosterols used for cholesterollowering (2.0-2.5 g/day) would be useful to evaluate the effects of phytosterols on immune function in humans.

\section{Anticancer activity of phytosterols and beneficial effects on prostatic hyperplasia}

The effects of plant sterols as anticancer compounds have been recently reviewed by Bradford and Awad [66]. Evidence for a protective role of especially plant sterols against various types of cancer in humans comes from epidemiological, case-control studies. In these studies, the consumption of total phytosterols was related, after controlling for major confounding factors, to a lower incidence of breast, lung, and stomach cancer [66]. Dietary intake of beta-sitosterol and stigmasterol was associated to lower risks of esophagus [67] and ovarian [68] cancer, respectively. On the other hand, a recent prospective cohort study failed to demonstrate a relationship between phytosterol intake and the risk of colon and rectal cancers [10]. Although the number of controlled studies is limited and the existence of a statistical relationship between phytosterol intake and a lower incidence of some cancers does not indicate a causal link, overall, the epidemiologic evidence suggests that phytosterols may exert a protective effect against certain types of cancer.

Additional evidence for the potential anticancer properties of phytosterols is provided by studies in animal models and in vitro experiments. Various studies in rats or mice administered carcinogenic stimuli, or injected or implanted with cancer cells showed that consumption of beta-sitosterol or a phytosterol mixture reduced the incidence of tumors, slowed down cell proliferation and/or lowered the number of metastases of colon, breast or prostate cancers [66]. Various mechanisms have been proposed to explain the potential anticancer properties of phytosterols: inhibition of cell cycle progression, promotion of cellular apoptosis possibly via activation of the sphingomyelin cycle and increased generation of ceramide, down-regulation of cholesterol synthesis, inhibition of cell invasion, migration and adhesion, as well as stimulation of the immune function $[66,69]$. A possible estrogenic activity of phytosterols could also be involved, but reports are inconsistent [66] and this mechanism of action seems less likely.

Clinical evidence is lacking for a role of phytosterols in the management of cancers. However, supplementation with phytosterols appears to be useful in the treatment of benign prostatic hyperplasia (BPH). Symptomatic BPH is a common medical condition in older men. A meta-analysis of four randomised, placebocontrolled, double blind trials showed that oral consumption of small doses (60-130 mg/day) of beta-sitosterol for 4 to 26 weeks improved the clinical symptoms of BPH (flow rate and residual urinary volume) without reducing the prostate size [70]. A subsequent study showed that the beneficial effects of $60 \mathrm{mg} /$ day betasitosterol were maintained over a period of 18 months [71]. This efficacy in improving the symptomatology of BPH is remarkable as such low doses of beta-sitosterol are small compared with the normal dietary intake of phytosterols 
estimated at $150-400 \mathrm{mg} /$ day. The mechanisms responsible for the putative beneficial effects of phytosterols on $\mathrm{BPH}$ remain unclear but may be related to an altered testosterone metabolism [72]. Moreover, data on long-term safety and ability to prevent complications related to BHP are lacking.

\section{Conclusion}

Phytosterols are naturally occurring compounds found in plants that include sitosterol and campesterol, and their saturated counterparts sitostanol and campestanol. Phytosterols have been used for the last half-century because of their cholesterol-lowering properties. They have been shown in a vast number of human studies to be safe and effective in lowering plasma total and LDL-cholesterol concentrations. The underlying mechanisms of the cholesterol-lowering action of phytosterols relate to the inhibition of intestinal cholesterol absorption. In addition to their well-established cholesterol-lowering effect, other potential health benefits of phytosterols have been described. However, evidence for such promising effects, e.g. antioxidant and antiinflammatory actions, as well as benefits on the immune system and anticancer properties are still at a rudimentary stage and more research is clearly needed to draw firm conclusions.

\section{REFERENCES}

1. PIIRONEN V, LINDSAY DG, MIETTINEN TA, TOIVO J, LAMPI AM. Plant sterols: biosynthesis, biological function and their importance to human nutrition. I Sci Food Agric 2000; 80: 939-66.

2. MOREAU RA, WHITAKER BD, HICKS KB. Phytosterols, phytostanols, and their conjugates in foods: structural diversity, quantitative analysis, and health-promoting uses. Prog Lipid Res 2002; 41: 457-500.

3. KATAN MB, GRUNDY SM, JONES P, LAW M, MIETTINEN T, PAOLETTI R. Efficacy and safety of plant stanols and sterols in the management of blood cholesterol levels. Mayo Clin Proc 2003; 78: 965-78.
4. KRITCHEVSKY D, CHEN SC. Phytosterols health benefits and potential concerns: a review. Nutr Res 2005; 25: 413-28.

5. PIIRONEN V, TOIVO I, PUUPPONEN-PIMIA R, LAMPI AM. Plant sterols in vegetables, fruits and berries. / Sci Food Agric 2003; 83: 330-7.

6. NORMÉN L, JOHNSSONM, ANDERSSONH, VAN GAMEREN Y, DUTTA P. Plant sterols in vegetables and fruits commonly consumed in Sweden. Eur / Nutr 1999; 38: 84-9.

7. NORMEN L, BRYNGELSSON S, JOHNSSON M, et al. The phytosterol content of some cereal foods commonly consumed in Sweden and in the Netherlands. J Food Compost Anal 2002; 15: 693-704.

8. LING WH, JONES PJ. Dietary phytosterols: a review of metabolism, benefits and side effects. Life Sci 1995; 57: 195-206.

9. OSTLUND IR. RE, MCGILL IB, ZENG CM, et al. Gastrointestinal absorption and plasma kinetics of soy Delta(5)-phytosterols and phytostanols in humans. Am J Physiol Endocrinol Metab 2002; 282: E911-E916.

10. NORMÉN AL, BRANTS HAM, VOORRIPS LE, ANDERSSON NA, VAN DEN BRANDT PA, GOLDBOHM RA. Plant sterol intakes and colorectal cancer risk in the Netherlands Cohort Study on Diet and Cancer. Am / Clin Nutr 2001; 74: 141-8.

11. BOSNERMS, LANGE LG, STENSON WF, OSTLUND RE. Percent cholesterol absorption in normal women and men quantified with dual stable isotopic tracers and negative ion mass spectrometry. J Lipid Res 1999; 40: 302-8.

12. BERGE KE, TIAN H, GRAF GA, et al. Accumulation of dietary cholesterol in sitosterolemia caused by mutations in adjacent $A B C$ transporters. Science 2000; 290: 1771-5.

13. NORMÉN L, FROHLICH J], TRAUTWEIN EA. Role of Plant Sterols in Cholesterol Lowering. In: Dutta PC, ed. Plant Sterols: Analytical, Nutritional, and Safety Aspects as Functional Food. New York: Marcel Dekker, 2004: 243-315.

14. TRAUTWEIN EA, DUCHATEAU GSMIE, LIN Y, MEL'NIKOV SM, MOLHUIZEN HOF, NTANIOS FY. Proposed mechanisms of Cholesterollowering action of Plant Sterols. Eur / Lipid Sci Technol 2003; 105: 171-85.

15. MEL'NIKOV SM, SEIIEN TEN, HOORN JW, EIJKELENBOOM AP. Effect of phytosterols and phytostanols on the solubilization of cholesterol by dietary mixed micelles: an in vitro study. Chem Phys Lipids 2004; 127: 121-41.

16. CHEN HC. Molecular mechanisms of sterol absorption. J Nutr 2001; 131: 2603-5.

17. VON BERGMANN K, SUDHOPT, LUTJOHANN D. Cholesterol and plant sterol absorption; recent insights. Am / Cardiol 2005; 96: $10-4$
18. DE JONGHS, VISSERS MN, ROL P, BAKKER HD, KASTELEIN JJP, STROES ESG. Plant sterols lower LDL cholesterol without improving endothelial function in prepubertal children with familial hypercholesterolaemia. / Inherit Metab Dis 2003; 26: 343-51

19. BERGER A, JONES PJ, ABUMWEIS SS. Plant sterols: factors affecting their efficacy and safety as functional food ingredients. Lipids Health Dis 2004; 7: 3-5.

20. POLLAK OJ. Reduction of Blood Cholesterol in Man. Circulation 1953; 7: 702-6.

21. RILEY FP, STEINER A. Effect of sitosterol on the concentration of serum lipids in patients with coronary atherosclerosis. Circulation 1957; 16: 723-9.

22. CLIFTON PM, NOAKES M, SULLIVAN D, et al. Cholesterol-lowering effects of plant sterol esters differ in milk, yoghurt, bread and cereal. Eur J Clin Nutr 2004; 58: 503-9.

23. NOAKES M, CLIFTON PM, DOORNBOS AM, TRAUTWEIN EA. Plant sterol ester-enriched milk and yoghurt effectively reduce serum cholesterol in modestly hypercholesterolemic subjects. Eur / Nutr 2005; 44: 214-22.

24. MENSINK RP, EBBING $S$, LINDHOUT M, PLAT J, VAN HEUGTEN MMA. Effects of plant stanol esters supplied in low-fat yoghurt on serum lipids and lipoproteins, non-cholesterol sterols and fat soluble antioxidant concentrations. Atherosclerosis 2002; 160: 205-13.

25. DOORNBOS AME, MEYNEN EM, DUCHATEAU GSMIE, VAN DER KNAAP HCM, TRAUTWEIN EA. Intake occasion affects the serum cholesterol lowering of a plant sterol-enriched single-shot yoghurt drink in mildly hypercholesterolaemic subjects. Eur / Clin Nutr 2006; 60: 325-33.

26. JONES PJ, VANSTONE CA, RAEINI-SARJAZ M, ST-ONGE MP. Phytosterols in low- and nonfat beverages as part of a controlled diet fail to lower plasma lipid levels. / Lipid Res 2003; 44: 1713-9.

27. DeVARAJ S, AUtret bC, JaLAL I. Reducedcalorie orange juice beverage with plant sterols lowers $\mathrm{C}$-reactive protein concentrations and improves the lipid profile in human volunteers. Am J Clin Nutr 2006; 84: 756-61.

28. THOMSEN AB, HANSEN HB, CHRISTIANSEN C, GREEN H, BERGER A. Effect of free plant sterols in low-fat milk on serum lipid profile in hypercholesterolemic subjects. Eur / Clin Nutr 2004; 58 : 860-70.

29. CHRISTIANSEN LI, LAHTEENMAKI PL, MANNELIN MR, SEPPANEN-LAAKSO TE, HILTUNEN RV, YLIRUUSI JK. Cholesterol-lowering effect of spreads enriched with microcrystalline plant sterols in hypercholesterolemic subjects. Eur / Nutr 2001; 40: 66-73. 
30. VANSTONE CA, RAEINI-SARJAZ M, PARSON$S$ WE, JONES PJ. Unesterified plant sterols and stanols lower LDL-cholesterol concentrations equivalently in hypercholesterolemic persons. Am J Clin Nutr 2002; 76: 1272-8.

31. HAYES KC, PRONCZUK A, PERLMAN D. Nonesterified phytosterols dissolved and recrystallized in oil reduce plasma cholesterol in gerbils and humans. J Nutr 2004; 134: 1395-9.

32. DE GRAAF J, DE SAUVAGE NOLTING PR, VAN DAM M, et al. Consumption of tall oil-derived phytosterols in a chocolate matrix significantly decreases plasma total and low-density lipoprotein-cholesterol levels. Br / Nutr 2002; 88: 479-88.

33. TAPOLA NS, LYYRA ML, KARVONEN HM, UUSITUPA MI, SARKKINENES. The effect of meat products enriched with plant sterols and minerals on serum lipids and blood pressure. Int J Food Sci Nutr 2004; 55: 389-97.

34. PLAT J, VAN ONSELEN EN, VAN HEUGTEN MM, MENSINK RP. Effects on serum lipids, lipoproteins and fat soluble antioxidant concentrations of consumption frequency of margarines and shortenings enriched with plant stanol esters. Eur I Clin Nutr 2000; 54: 671-7.

35. MATVIENKO OA, LEWIS DS, SWANSON M, et al. A single daily dose of soybean phytosterols in ground beef decreases serum total cholesterol and LDL cholesterol in young, mildly hypercholesterolemic men. Am / Clin Nutr 2002; 76: 57-64.

36. JONES PJ, NTANIOS FY, RAEINI-SARJAZ M, VANSTONE CA. Cholesterol-lowering efficacy of a sitostanol-containing phytosterol mixture with a prudent diet in hyperlipidemic men. Am J Clin Nutr 1999; 69: 1144-50.

37. JENKINS D], KENDALL CW, MARCHIE A, et al. Direct comparison of a dietary portfolio of cholesterol-lowering foods with a statin in hypercholesterolemic participants. Am / Clin Nutr 2005; 81: 380-7.

38. JENKINS D], KENDALL CW, FAULKNER DA, et al. Assessment of the longer-term effects of a dietary portfolio of cholesterol-lowering foods in hypercholesterolemia. Am / Clin Nutr 2006; 83: 582-91.

39. MIETTINEN TA, PUSKA P, GYLLING H, VANHANEN H, VARTAINEN E. Reduction of serum cholesterol with sitostanol-ester maragrine in a mildly hypercholesterolemic population. $N$ Engl J Med 1995; 333: 1308-12.

40. HENDRIKS HFJ, BRINK EJ, MEIJER GW, PRINCEN HMG, NTANIOS FY. Safety of long-term consumption of plant sterol esters-enriched spread. Eur J Clin Nutr 2003; 57: 681-92.

41. SIMONS LA. Additive effect of plant sterol-ester margarine and cerivastatin in lowering lowdensity lipoprotein cholesterol in primary hypercholesterolemia. Am / Cardiol 2002; 90: 737-40.
42. NIGON F, SERFATY-LACROSNIÈRE C, BEUCLER I, et al. Plant sterol-enriched margarine lowers plasma LDL in hyperlipidemic subjects with low cholesterol intake: effect of fibrate treatment. Clin Chem Lab Med 2001; 39: 634-40.

43. JAKULJ L, TRIP MD, SUDHOP T, VON BERGMANN K, KASTELEIN J], VISSERS MN. Inhibition of cholesterol absorption by the combination of dietary plant sterols and ezetimibe: effects on plasma lipid levels. J Lipid Res 2005; 46: 2692-8.

44. EDWARDS JE, MOORE RA. Statins in hypercholesterolaemia: a dose-specific meta-analysis of lipid changes in randomised, double blind trials. BMC Fam Pract 2003; 4: 18.

45. MOGHADASIAN MH, MCMANUS BM, PRITCHARD PH, FROHLICH JJ. Tall oil"'-derived phytosterols reduce atherosclerosis in ApoEdeficient mice. Arterioscler Thromb Vasc Biol 1997; 17: 119-26.

46. NTANIOS FY, JONES PJH. Effects of variable dietary sitostanol concentrations on plasma lipid profile and phytosterol metabolism in hamsters. Biochim Biophys Acta 1998; 1390: 237-44.

47. MOGHADASIAN MH, MCMANUS BM, GODIN DV, RODRIGUES B, FROHLICH JJ. Proatherogenic and antiatherogenic effects of probucol and phytosterols in apolipoprotein E-deficient mice - Possible mechanisms of action. Circulation 1999; 99: 1733-9.

48. MOGHADASIAN MH, GODIN DV, MCMANUS $B M$, et al. Lack of regression of atherosclerotic lesions in phytosterol treated apoE deficient mice. Life Sci 1999; 64: 1029-36.

49. NTANIOS FY, VAN DER KOOIJ A, DE DECKERE AM, DUCHATEAU GSMIE, TRAUTWEIN EA. Effects of various amounts of dietary plant sterol esters on plasma and hepatic sterol concentration and aortic foam cell formation of cholesterol-fed hamsters. Atherosclerosis 2003; 169: 41-50.

50. VOLGER OL, MENSINK RP, PLAT I, HORNSTRA G, HAVEKES LM, PRINCEN HMG. Dietary vegetable oil and wood derived plant stanol esters reduce atherosclerotic lesion size and severity in apoE*3- Leiden transgenic mice. Atherosclerosis 2001; 157: 375-81.

51. WILUND KR, YU L, XU F, et al. No association between plasma levels of plant sterols and atherosclerosis in mice and men. Arterioscler Thromb Vasc Biol 2004; 24: 2326-32.

52. PLAT J, BEUGELS I, GIJBELS MJ, DE WINTHER MP, MENSINK RP. Plant sterol or stanol esters retard lesion formation in LDL receptordeficient mice independent of changes in serum plant sterols. J Lipid Res 2006; 47: 2762 71.

53. POLLAK O], KRITCHEVSKY D. Sitosterol. In: Monogr Atheroscler. Basel: Karger, 1981.
54. AWAD AB, SMITH AJ, FINK CS. Plant sterols regulate rat vascular smooth mulscle cell growth and prostacyclin release in culture. Prostaglandins Leukot Essent Fatty Acids 2001; 64: 323-30.

55. AWAD AB, TOCZEK I, FINK CS. Phytosterols decrease prostaglandin release in cultured P388D(1)/MAB macrophages. Prostaglandins Leukot Essent Fatty Acids 2004; 70: 511-20.

56. PLAT J, MENSINK RP. Vegetable oil based versus wood based stanol ester mixtures: effects on serum lipids and hemostatic factors in nonhypercholesterolemic subjects. Atherosclerosis 2000; 148: 101-12.

57. DE JONG A, PLAT J, BAST A, GODSCHALK RW, BASU S, MENSINK RP. Effects of plant sterol and stanol ester consumption on lipid metabolism, antioxidant status and markers of oxidative stress, endothelial function and low-grade inflammation in patients on current statin treatment. Eur / Clin Nutr 2007; (Epub ahead of print).

58. JAKULJ L, VISSERS MN, RODENBURG J, WIEGMAN A, TRIP MD, KASTELEIN JJ. Plant stanols do not restore endothelial function in prepubertal children with familial hypercholesterolemia despite reduction of low-density lipoprotein cholesterol levels. J Pediatr 2006; 148: 495-500.

59. HOMMA Y, IKEDA I, ISHIKAWA T, TATENO M, SUGANO M, NAKAMURA $\mathrm{H}$. Decrease in plasma low-density lipoprotein cholesterol, apolipoprotein B, cholesteryl ester transfer protein, and oxidized low-density lipoprotein by plant stanol ester- containing spread: A randomized, placebo-controlled trial. Nutrition 2003; 19: 369-74

60. BOUIC PJD. The role of phytosterols and phytosterolins in immune modulation: a review of the past 10 years. Curr Opin Clin Nutr Metab Care 2001; 4: 471-5.

61. YUK JE, WOO JS, YUN CY, et al. Effects of lactose-beta-sitosterol and beta-sitosterol on ovalbumin-induced lung inflammation in actively sensitized mice. Int Immunopharmacol 2007; 7: 1517-27.

62. NAVARRO A, DE LAS HERAS B, VILLAR A. Antiinflammatory and immunomodulating properties of a sterol fraction from Sideritis foetens Clem. Biol Pharm Bull 2001; 24: 470-3.

63. MAVAR-MANGA H, HADDAD M, PIETERS $L$, BACCELLI C, PENGE A, QUETIN-LECLERCQ J. Anti-inflammatory compounds from leaves and root bark of Alchornea cordifolia (Schumach. \& Thonn.) Müll. Arg. J Ethnopharmacol 2007(Sep): 4; (Epub ahead of print).

64. CALPE-BERDIEL L, ESCOLÀ-GIL JC, BENITTEZ S, et al. Dietary phytosterols modulate T-helper immune response but do not induce apparent anti-inflammatory effects in a mouse model of acute, aseptic inflammation. Life Sci 2007; 80: 1951-6. 
65. BOUIC PJ. Sterols and sterolins: new drugs for the immune system? Drug Discov Today 2002; 7: $775-8$.

66. BRADFORD PG, AWAD AB. Phytosterols as anticancer compounds. Mol Nutr Food Res 2007; 51: 161-70.

67. DE STEFANI E, BRENNAN $P$, BOFFETTA P, RONCO AL, MENDILAHARSU M, DENEOPELLEGRINI H. Vegetables, fruits, related dietary antioxidants, and risk of squamous cell carcinoma of the esophagus: a case-contro study in Uruguay. Nutr Cancer 2000; 38: 23-9.

68. MCCANN SE, FREUDENHEIM JL, MARSHALL JR, GRAHAM S. Risk of human ovarian cancer is related to dietary intake of selected nutrients, phytochemicals and food groups. / Nutr 2003; 133: $1937-42$.

69. AWAD AB, WILLIAMS H, FINK CS. Effect of phytosterols on cholesterol metabolism and MAP kinase in MDA-MB-231 human breast cancer cells. J Nutr Biochem 2003; 14: 111-9.
70. WILTTI, MACDONALD R, ISHANIA. betasitosterol for the treatment of benign prostatic hyperplasia: a systematic review. BJU Int 1999; 83: 976-83.

71. BERGES RR, KASSEN A, SENGE T. Treatment of symptomatic benign prostatic hyperplasia with beta-sitosterol: an 18-month follow-up. BJU Int 2000; 85: 842-6.

72. AWAD AB, GARCIA MD, FINK CS. Effect of dietary phytosterols on rat tissue lipids. Nutr Cancer 1997; 29: 212-6. 